\title{
An Evidence-based General Anesthesia and Prone Position Nursing Checklist: Development and Testing
}

Jianshu Cai

Sir Run Run Shaw Hospital

Xiaoling Huang

Sir Run Run Shaw Hospital

Lifang He ( 3316113@zju.edu.cn )

Xiangnan University

\section{Research Article}

Keywords: prone position, Delphi survey, checklist, evidence-based nursing, patient safety

Posted Date: December 7th, 2021

DOI: https://doi.org/10.21203/rs.3.rs-1120545/v1

License: (c) (1) This work is licensed under a Creative Commons Attribution 4.0 International License.

Read Full License 


\section{Abstract}

Background and Aim: Prone positioning during general anesthesia is one of the most difficult practices for the perioperative nurse. Patients in this position are vulnerable to many preventable complications. However, no studies have developed an evidenced-based tool to improve nursing practice during general anesthesia and prone positioning. This study aimed to develop and test a general anesthesia and prone position nursing checklist for use by the circulating nurse.

Methods: The WHO checklist development model and evidence-based methods guided the checklist development process. A prospective pre-post study was performed between November 2020 and March 2021. We prospectively observed circulating nurses that attended to prone general anesthesia during posterior lumbar spine surgery for three months before and after the introduction of the general anesthesia and prone position nursing risk checklist. The main outcomes were successful delivery of essential prone positional nursing practices during each surgery and the nurse's opinion of the checklist's efficacy and utility.

Results: A general anesthesia and prone position nursing checklist comprised of 4 pause points and 22 necessary nursing practices was developed. Seventy-two nurses participated in this study. Use of the checklist significantly increased the average performance of essential practices during each surgery from $72.72 \%$ to $95.45 \%$. Three measures had a compliance rate of $100 \%$. The delivery rate of 14 measures was significantly improved, $91.7 \%$ of nurses considered the checklist easy to use, and $94.4 \%$ nurses would want the checklist to be used if they underwent a prone position and general anesthesia operation.

Conclusions: A general anesthesia and prone position nursing checklist was developed. The instrument was found to be an effective and positively received tool for facilitating key measures of prone positioning during nursing care, translating evidence into practice, and standardizing the nursing process.

\section{Introduction}

General anesthesia with patients in the prone position is one of the most commonly used and difficult surgical positions, and is required during many types of spinal, neurosurgery, and urinary procedures[1]. The patient under general anesthesia in the prone position is vulnerable to multiple injuries, including pressure injuries $(\mathrm{PI})$, postoperative vision loss (POVL), perioperative peripheral nerve injuries (PPNI), tongue swelling resulting in airway compromise and even permanent disability[1-3]. Most of these types of injuries are well-understood and largely avoidable by following clinical practice guidelines (CPG). However, the complication rate during prone surgery continues to increase rapidly according to recent survey studies[4,5]. Poor quality care during prone surgery is recognized as a significant contributing factor to these injuries. Prior work showed that $73 \%$ of the operating room (OR) nurses did not have adequate knowledge about how to prevent perioperative $\mathrm{PI}$, and their ability to identify risks for $\mathrm{PI}$ was also limited[6]. OR nurses also lack an evidence-based tool and method to help them provide optimal 
prone position nursing practices[7]. Enhancing OR nurses' skills for managing patients in the prone position is necessary to prevent injuries. However, no widely applicable method or tool currently exists.

Checklists had been used for many decades in aviation, construction, and other non-medical areas to guide users when completing tasks during which errors or omissions can be fatal[8]. The WHO defined medical checklists as useful tools for bridging the gap between evidence and safe daily practices[9]. Various evidence-based medical checklists have been developed and used around the world to promote the delivery of high-quality health care in different surgical and hospital settings[10,11]. These checklists can standardize health care, reduce complications, and save lives[12]. Two studies designed checklists for anesthesia practitioners and ICU practitioners to provide proper prone positioning techniques $[8,13]$. Use of these two checklists can effectively improve prone positioning care safety and set up a standard prone positioning procedure. However, both checklists were based on unevaluated evidence and their target users were not circulating nurses. Further, traditional prone position nursing courses and studies usually focus on prone positioning methods, complications, and preventive measures, and ignored the high-risk factors and countermeasures during each stage of prone positioning[7, 14, 15]. As a result, the nurse's prone positioning theoretical and practice level usually relies on their own knowledge and experience. It is therefore necessary to develop a checklist for the circulating nurse to help them provide continuous, comprehensive, and evidence-based prone positioning care during daily practice.

The circulating nurse in particular plays a critical role in surgical patient prone positioning. The circulating nurse must balance surgical comfort with optimal exposure of the surgical site, airway management, ventilation, and monitoring access for the anesthesia care provider while minimizing the risk of injury to the patient[16]. It is critical for the circulating nurse to deliver standardized and scientific interventions when the patient is in the prone position. This study aimed to design and implement an evidence-based general anesthesia and prone position nursing checklist (GAPPNC) to improve the circulating nurse's delivery of standard prone positional nursing practices in order to increase patient safety.

\section{Theoretical Framework}

The study followed the WHO recommended checklist development model (Figure 1) and the WHO Safe Childbirth Checklist development study $[17,18]$. A checklist is a set list used to identify, schedule, or verify a group of elements or key points, and is used as a visual or oral aid to supplement the user's memory. A medical checklist improves the provision of care and guides the medical staff towards consistently following a core set of safety practices to minimize the most common and avoidable medical errors that can endanger the patient's life and wellbeing[19]. WHO-designed checklists and its checklist development model have received global recognition[20, 21]. Weiser and Spector described the WHO methodology as the basis for content and critical implementation components of a checklist development program in order to help inform health workers in the design of different medical checklists $[17,18]$.

\section{Materials And Methods}




\section{Study Design}

We aimed to develop a nursing checklist for general anesthesia during prone position surgery using the WHO checklist development model and evidence-based methods. The study consisted of two phases: 『development of a GAPPNC, \testing the feasibility of using the GAPPNC.

\section{GAPPNC Development}

\section{Establishment of a Multidisciplinary Development Team}

A multidisciplinary development team including the OR nursing manager, director of orthopedics, director of anesthesiology, and hospital administrative coordinator was established. The team's responsibilities included reviewing the guidelines for general anesthesia in the prone position, drafting the first edition of the checklist, assembling expert consultation, iterative refinement through consultation, evaluating checklist feasibility.

\section{Literature Review and Quality Evaluation}

A comprehensive literature review of the major causes of general anesthesia prone position complications and a review of existing CPGs that targeted these major complications was compiled in a background document. This document was critical for not only establishing goals for improvement but also for highlighting the specific practices necessary to achieve these goals. The background document also suggested additional topics for consideration as part of the checklist $[17,18]$. The document was circulated to all confirmed participants in the Delphi consultation. The following electronic databases were systematically searched for CPGs: Chinese Biomedical Literature Database, the VIP Database, Wanfang Database, Google Scholar, Joanna Briggs Institutions, PubMed, National Guideline Clearinghouse, and WHO. Search terms included general anesthesia, positioning, surgical position, patient positioning, prone, prone position, positioning injury, pressure injury, postoperative vision loss, perioperative neuropathy injury, circulating nurse, operative nurse, perioperative nurse, perioperative nursing, clinical practice guidelines, practice guidelines, and advisory. The inclusion criteria were that the guidelines needed to be published in either the English or Chinese language before June 2020 and deal with general anesthesia and prone positioning interventions in the OR. Articles with an AGREE II overall score less than $70 \%$ were excluded so that guidelines with the highest possible quality could be chosen. The AGREE II instrument was developed to assess the quality of guidelines. It is an effective and reliable tool that consists of 23 items organized into six domains[22]. Two researchers independently used the AGREE II instrument to appraise the identified guidelines.

\section{Identify Critical Omissions and Draw Up the Checklist}

According to Weiser's study, the overall goal during the development of a medical checklist was to focus only on 'killer items' that are most critical, known to be often overlooked, and put the patient at the highest risk of harm when ignored[17]. Critical omissions during general anesthesia prone position surgery identified by the team included electric burns, pressure injury, postoperative vision loss, spinal injury, 
perioperative neuropathy, and accidental falls. The scope of application of the checklist was found to be applicable to ORs in China, and the target users were determined to be the circulating nurses in the OR. The sequence of checking entries in the checklist must follow the actual workflow of the circulating nurse and be within his or her area of responsibility. Based on these key demands, the core team extracted and summarized evidence from 6 guidelines to develop the first edition of the GAPPNC, which consisted of 21 items.

\section{Delphi Expert Consultation}

Delphi expert consultation was used to collect expert judgments and compare the aggregate judgments of all experts until a consensus criterion is reached. The criteria for selecting experts included: a) an intermediate technical title or higher, $b$ ) a bachelor's degree or higher, $c$ ) more than 20 years of experience in the profession, and d) were familiar with the Delphi method and volunteered for this survey. All experts worked anonymously and independently.

An expert consultation questionnaire was developed by the core team and sent to the experts via e-mail. The draft checklist's constructs and subconstructs were presented to the experts during the first Delphi round, and the experts were asked to comment on the checklist and its constructs and subconstructs. They were also asked to comment on the rationality, comprehensiveness, suitability, and applicability of the proposed checklist in OR, and whether there were items that needed to be modified, deleted, or added. Expert responses were reviewed and integrated into the second draft of the checklist, which was presented to the Delphi panelists during the second round together with the revised expert consultation questionnaire. The experts were asked to re-evaluate each item during the second round. The second Delphi round resulted in consensus on the checklist content.

\section{Field Test}

To pretest the applicability and feasibility of the checklist, the checklist was used in a total of 20 prone position and general anesthesia posterior lumbar spine surgeries over the course of two weeks. Nurse evaluation and feedback were collected, and the team modified the checklist according to that feedback.

\section{Application of the GAPPNC for 6 Months}

A six-month prospective pre-post study was performed to assess the feasibility of the GAPPNC at Sir Run Run Shaw Hospital, which is affiliated with Medical College of Zhejiang University in China. We planned to observe circulating nurses that attended to general anesthesia and posterior lumbar spine surgery in the prone position for three months from November to December 2020, and then monitor them attending to the same events using the newly developed checklist for three months from January to March 2021. Circulating nurses were eligible for inclusion in the study if, a) they were a registered nurse at the study site with more than two years of OR work experience, b) they completed training related to this study and passed the required assessment, and c) they volunteered to participate in the study and completed the informed consent form. The exclusion criteria were OR head nurse and nurse who quit halfway. 
The study site was selected based on its sufficient volume of general anesthesia and prone position surgery, the general availability of supplies, its motivated leadership, and the absence of other ongoing interventions. One investigator of the multi-disciplinary team introduced the checklist to the circulating nurses during the one-day learning session and monitored its ongoing use. Learning was supported by lectures, written materials, an instructional video, and direct guidance. The OR nursing department was responsible for the endorsement of the checklist.

\title{
Data Collection
}

Patient demographic characteristics were collected from the electronic medical record system. One nursing college student who was free of responsibility at the study hospital and unknown to the circulating nurses was chosen to be the data collector and taught by the investigator to observe and document the circulating nurse's practice during the procedure. Nursing practice was considered to be performed when the nurse correctly performed the appropriate practice during the required period of verification. Failure to perform measures, such as due to an omission, error, or failure to perform the action during the correct period of time, was considered non-performance. Observation data were recorded on standardized data sheets by data collectors who directly observed the nurses. The observation took place over a 12 hours period on weekdays from the time the patient entered the OR to before the patient left the OR. Checklist use was observed during the post-intervention period. Data collectors did not interact with circulating nurses or patients during their observation. For ethical reasons, data collectors would notify nurses if they observed a potentially harmful condition or practice. Nurse evaluation of the checklist consisted of six items specifically related to the checklist intervention developed by the core team ('The checklist was easy to use, 'The checklist improved prone position safety,' 'The checklist improved prone position nursing care quality,' 'The checklist took a long time to complete, 'If I were having a prone position and general anesthesia operation, I would want the checklist to be used,' and 'The checklist helped prevent prone position injury') and were included only in the post intervention version of the survey. One item (The checklist took a long time...') was reverse-scored to calculate summary statistics.

\section{Statistical analysis}

Analyses were performed using SPSS20.0 software (IBM Corp. Armonk, NY: IBM Corp). Chi-Squared tests were used to test whether the delivery rate had different distributions before and after implementing the new checklist. A P-value less than 0.05 was considered significant.

\section{Results}

\section{Checklist Development}

\author{
Literature Review and Quality Evaluation
}


A total of 925 guidelines were initially obtained from the databases. 10 guidelines that addressed general anesthesia and the prone position and were assessed with the AGREE II instrument. 6 guidelines(Table S1)fulfilled the inclusion criteria (see Figure 2 for the search process). Table S2 shows the scores obtained using the guidelines as percentage scores.

\section{Delphi Expert Consultation}

A two-round Delphi expert consultation was performed to explore the views of experts on issues relating to this study. Twenty experts with sound theoretical knowledge and excellent practical skills in OR nursing, orthopedics, and anesthesiology were selected. The average age of the experts was 43 and their average working time was 20.2 years. They worked in different regions of China: Hangzhou (8), Huzhou (5), Nanchang (4), Wuhan (3). After two Delphi rounds, the panelists identified four pause points and revised two items in the draft. A pause point is the point in the process of caring for a patient when it is appropriate to pause to check that the item on the checklist has been completed. The four pause points were "before prone positioning," "after prone positioning," "during the operation," and "before leaving the operating room." Two items were modified, "four caregivers should be available for a supine-to-prone patient transfer" was changed to "four caregivers must be available for a supine-to-prone patient transfer, including an anesthetist responsible for the patient's head and tube", because four caregivers are much safer for supine-to-prone patient positioning. The other change was from "when operating time is longer than 3 hours, reposition the patient every two hours" to "when operating time is longer than 3 hours, communicate with the anesthetist and the surgeon as to whether the patient should be repositioned every two hours", because if the patient position is changed without communication with anesthetist and surgeon, surgical safety and anesthesia tube position may be jeopardized. Based on the results of the Delphi round the second edition of GAPPNC was confirmed, which included four pause points and 21 practices (Table S3).

\section{Field Test}

Nurse evaluations of the checklist were as follows: the average time taken to complete the checklist was 3.5 minutes per phase; the content of the checklist was complete and its items were logically arranged, and the guidelines were expressed in a concise and clear manner. Two suggestions were proposed. The team members discussed the nurses' feedback and made two modifications. The first was to add an item during the immediate after prone positioning period that states that "Parts of the body that do not require treatment are covered." The nurse thought this item was easy to forget but important for patient warmth. The CPGs also mentioned that unnecessary exposure of patients during patient positioning should be avoided, and that covering the patient not only protected their privacy but also benefited their early postoperative recovery[23]. The second change was that "assess the patient's vision after recovery" was changed to "Inform the postanesthesia care unit (PACU) staff that patient'vision and peripheral nerve function must be assessed after recovery as the nurses believed that most patients were still under anesthetic before leaving the OR, it was best to remind the PACU staff to complete this task to improve OR efficiency. After these revisions, the final edition of the GAPPNC (Table 1) included 22 measures over 
four stages: before prone positioning ( 5 items), after prone positioning (12 items), during operation (3 items), and before leaving the OR ( 2 items). Content involved standard patient positioning, privacy protection, hypothermia prevention, patient assessment, electric surgical safety, prevention of peripheral nerve and optic nerve injury, and perioperative stress. The content also covered the most basic and necessary nursing interventions to avoid preventable complications from the prone position. 
Table 1

Final Edition of the GAPPNC

\section{Before prone positioning}

Positioning equipment is available, dry, smooth and intact, and in proper function

\section{Yes}

The patient is in limitation of motion

Yes

No

The patient's skin is intact

\section{$\square$ Yes}

No

Operating bed and transport vehicle are locked, side rails are raised

\section{Yes}

Four caregivers must be available for a supineto-prone patient transfer (a anesthetist responsible for the patient's head and tube)

Yes

\section{After prone positioning}

Head is level with or higher than heart $\square$ Yes

Head, neck, and trunk are a neutral position $\square$ Yes

All the tubes are intact and function properly $\square$ Yes

The padded headrest, chest rolls (i.e., from clavicle to iliac crest), and safety trap (i.e., $5 \mathrm{~cm}$ above the knee) are used $\square$ Yes

Positioning equipment is smooth and dry $\square$ Yes

Eyes are closed and uncompressed $\square$ Yes

Arms are placed on padded boards with the arms abducted to less than 90 degrees or placed at the side of the body, with the elbows flexed and the palms facing downwards $\square$ Yes

Body is protected from touching metal portions of the procedure bed $\square$ Yes

Face, breast, or male genitalia are free from torsion or pressure $\square$ Yes

Shins are padding high enough to avoid pressure on the tips of the toes $\square$ Yes

Elbows, hands and knees are padded $\square$ Yes

Parts of the body that do not require treatment are covered $\square$ Yes

\section{Before leaving the operating room}

\section{During operation}




\section{Before prone positioning}

Remind doctors not to put pressure on patients when not operating (i.e., lean on patients,

surgical instruments, objects on patients)

Yes

Not applicable

Operating time is longer than 3 hours

$\square$ Yes, when operating time is longer than 3 hours, communicate with the anesthetist and the surgeon as to whether the patient should be repositioned every two hours

No, less than 3 hours

Reassess all the items of the second stage after repositioning or any movement of the patient, procedure bed, or equipment attaches to the bed

\section{After prone positioning}

Patient developed new pressure injury

$\square$ Yes

$\square$ No

Inform the postanesthesia care unit (PACU) staff that

patient'svision and peripheral nerve function must be

assessed after recovery

$\square$ Yes

Yes, already reassessed

Not applicable

\section{Checklist Testing}

\section{Demographic Characteristics}

We observed 72 nurses attending to 84 surgeries during the baseline period (November-December, 2020), and 87 surgeries after introduction of the checklist (January-March, 2021). Table 2 lists patient characteristics. There were no significant differences between the patients in the two phases of the study. All nurses involved in the study were invited to participate and agreed to do so, and there was no nurse turnover during this study. Nurse demographic characteristics are shown in Table 3 . The pre- and postintervention periods did not overlap, and data was not collected during the brief period when the program was introduced. 
Table 2

Patient Demographics Before and After Checklist Implementation

\begin{tabular}{|c|c|c|c|}
\hline Characteristics & Before $(n=84)$ & After $(n=87)$ & $P$ value \\
\hline Age & $55.94 \pm 6.77$ & $55.15 \pm 7.01$ & 0.499 \\
\hline \multicolumn{4}{|l|}{ Sex (\%) } \\
\hline Female & 38.10 & 41.38 & \multirow[t]{2}{*}{0.661} \\
\hline Male & 61.90 & 58.62 & \\
\hline Body mass index (BMI) & $22.22 \pm 3.80$ & $22.77 \pm 3.24$ & 0.163 \\
\hline Operative duration (min) & $184.07 \pm 31.18$ & $191.01 \pm 32.59$ & 0.573 \\
\hline
\end{tabular}


Table 3

Nurse Demographics( $\mathrm{n}=72)$

\begin{tabular}{|c|c|}
\hline Characteristics & $\mathrm{N}($ percentage $)$ \\
\hline \multicolumn{2}{|l|}{ Gender } \\
\hline Male & $9(12.50 \%)$ \\
\hline Female & $63(87.50 \%)$ \\
\hline \multicolumn{2}{|l|}{ Age } \\
\hline $22 \sim 29$ & $33(45.83 \%)$ \\
\hline 30 39 & 27 (37.50\%) \\
\hline $40 \sim 49$ & 10(13.89\%) \\
\hline$\geq 50$ & $2(2.78 \%)$ \\
\hline \multicolumn{2}{|l|}{ Years of Working } \\
\hline $3-5$ & $21(29.17 \%)$ \\
\hline $5-10$ & $35(48.61 \%)$ \\
\hline >10 & $16(22.22 \%)$ \\
\hline \multicolumn{2}{|l|}{ Job Title } \\
\hline Junior nurse & $6(8.33 \%)$ \\
\hline Senior nurse & $43(59.72 \%)$ \\
\hline Supervisor nurse & $23(31.94 \%)$ \\
\hline \multicolumn{2}{|l|}{ Education level } \\
\hline College degree & $13(18.06 \%)$ \\
\hline Bachelors degree & $54(75.00 \%)$ \\
\hline Master or above & 5 (6.94\%) \\
\hline
\end{tabular}

Feasibility and Evaluation of the Checklist

There was a significant difference in the rate of successful delivery of essential prone positional nursing practices following the introduction of the checklist. Sixteen out of 22 essential practices were performed prior to use of the checklist, yielding an implementation rate of $72.72 \%$. With the use of the checklist, an average of 21 essential practices were implemented, resulting in an implementation rate of $95.45 \%$ and an increase of $22.73 \%$ in the implementation of measures $\left(X^{2}=4.247, P=0.039\right)$.

Table 4 shows the rates of successful completion of individual practices before and after introduction of the checklist. Compliance rates for three measures were $100 \%$ and delivery rates for 14 practices 
improved significantly, including items 1, 2, 3, 10, 11, 13, 14, 16, 17, 18, 19, 20, 21 and 22. 
Table 4

Changes in the Delivery of Specific Practices Before and After Intervention

\begin{tabular}{|c|c|c|c|c|c|c|}
\hline \multirow[t]{2}{*}{ Intervention ( $\mathrm{n=22}$ ) } & \multicolumn{2}{|l|}{ Before } & \multicolumn{2}{|l|}{ After } & \multirow[t]{2}{*}{$\chi^{2}$} & \multirow[t]{2}{*}{$P$} \\
\hline & Number & $\begin{array}{l}\text { Rates } \\
\text { of } \\
\text { Delivery }\end{array}$ & Number & $\begin{array}{l}\text { Rates of } \\
\text { Delivery }\end{array}$ & & \\
\hline $\begin{array}{l}1 \text { Positioning equipment is } \\
\text { available, dry, smooth and intact, } \\
\text { and in proper function }\end{array}$ & $64 / 84$ & $76.19 \%$ & $85 / 87$ & $97.70 \%$ & 17.640 & 0.000 \\
\hline 2 The patient is in limitation & $22 / 84$ & $26.19 \%$ & $80 / 87$ & $91.95 \%$ & 76.792 & 0.000 \\
\hline 3 The patient's skin is intact & $65 / 84$ & $77.38 \%$ & $87 / 87$ & $100.00 \%$ & 22.138 & 0.000 \\
\hline $\begin{array}{l}4 \text { Operating bed and transport } \\
\text { vehicle are locked, side rails are } \\
\text { raised }\end{array}$ & $81 / 84$ & $96.43 \%$ & $86 / 87$ & $98.85 \%$ & 1.097 & 0.295 \\
\hline $\begin{array}{l}5 \text { Four caregivers must be } \\
\text { available for a supine-to-prone } \\
\text { patient transfer }\end{array}$ & $70 / 84$ & $83.33 \%$ & $79 / 87$ & $90.80 \%$ & 2.128 & 0.145 \\
\hline $\begin{array}{l}6 \text { Head is level with or higher than } \\
\text { heart }\end{array}$ & $78 / 84$ & $92.86 \%$ & $82 / 87$ & $94.25 \%$ & 0.138 & 0.710 \\
\hline $\begin{array}{l}7 \text { Head, neck, and trunk are in a } \\
\text { neutral }\end{array}$ & $82 / 84$ & $97.62 \%$ & $87 / 87$ & $100.00 \%$ & 2.096 & 0.148 \\
\hline $\begin{array}{l}8 \text { All the tubes are intact and } \\
\text { function properly }\end{array}$ & $77 / 84$ & $91.67 \%$ & $83 / 87$ & $95.40 \%$ & 0.991 & 0.320 \\
\hline $\begin{array}{l}9 \text { The padded headrest, chest rolls } \\
\text { and safety trap are used }\end{array}$ & $75 / 84$ & $89.29 \%$ & $79 / 87$ & $90.80 \%$ & 0.110 & 0.740 \\
\hline $\begin{array}{l}10 \text { Positioning equipment is } \\
\text { smooth and dry }\end{array}$ & $47 / 84$ & $55.95 \%$ & $83 / 87$ & $95.40 \%$ & 36.489 & 0.000 \\
\hline $\begin{array}{l}11 \text { Eyes are closed and } \\
\text { uncompressed }\end{array}$ & $56 / 84$ & $66.67 \%$ & $84 / 87$ & $96.55 \%$ & 25.717 & 0.000 \\
\hline $\begin{array}{l}12 \text { Arms are placed on padded } \\
\text { boards with the arms abducted to } \\
\text { less than } 90 \text { degrees with the } \\
\text { elbows flexed and the palms } \\
\text { facing downwards }\end{array}$ & $67 / 84$ & $79.76 \%$ & $75 / 87$ & $86.21 \%$ & 1.261 & 0.262 \\
\hline $\begin{array}{l}13 \text { Body is protected from } \\
\text { touching metal portions of the } \\
\text { procedure bed }\end{array}$ & $80 / 84$ & $95.24 \%$ & $87 / 87$ & $100.00 \%$ & 4.242 & 0.039 \\
\hline $\begin{array}{l}14 \text { Face, breast, or male genitalia } \\
\text { are free from torsion or pressure }\end{array}$ & $72 / 84$ & $85.71 \%$ & $83 / 87$ & $95.40 \%$ & 4.729 & 0.030 \\
\hline
\end{tabular}




\begin{tabular}{|c|c|c|c|c|c|c|}
\hline \multirow[t]{2}{*}{ Intervention $(n=22)$} & \multicolumn{2}{|l|}{ Before } & \multicolumn{2}{|l|}{ After } & \multirow[t]{2}{*}{$x^{2}$} & \multirow[t]{2}{*}{$P$} \\
\hline & Number & $\begin{array}{l}\text { Rates } \\
\text { of } \\
\text { Delivery }\end{array}$ & Number & $\begin{array}{l}\text { Rates of } \\
\text { Delivery }\end{array}$ & & \\
\hline $\begin{array}{l}15 \text { Shins are padding high enough } \\
\text { to avoid pressure on the tips of the } \\
\text { toes }\end{array}$ & $74 / 84$ & $88.10 \%$ & $81 / 87$ & $93.10 \%$ & 1.264 & 0.261 \\
\hline $\begin{array}{l}16 \text { Elbows, hands and knees are } \\
\text { padded }\end{array}$ & $62 / 84$ & $73.81 \%$ & $82 / 87$ & $94.25 \%$ & 13.433 & 0.000 \\
\hline $\begin{array}{l}17 \text { Parts of the body that do not } \\
\text { require treatment are covered }\end{array}$ & $65 / 84$ & $77.38 \%$ & $85 / 87$ & $97.70 \%$ & 16.381 & 0.000 \\
\hline $\begin{array}{l}18 \text { Remind doctors not to put } \\
\text { pressure on patients when not } \\
\text { operating }\end{array}$ & $13 / 50$ & $26.00 \%$ & $33 / 43$ & $76.74 \%$ & 23.814 & 0.000 \\
\hline $\begin{array}{l}19 \text { Operating time is longer than } 3 \\
\text { hours }\end{array}$ & $4 / 42$ & $9.52 \%$ & $33 / 47$ & $70.21 \%$ & 33.632 & 0.000 \\
\hline $\begin{array}{l}20 \text { Reassess all the items of the } \\
\text { second stage after repositioning or } \\
\text { any movement of the patient, } \\
\text { procedure bed, or equipment } \\
\text { attaches to the bed }\end{array}$ & $2 / 25$ & $8.00 \%$ & $15 / 19$ & $78.95 \%$ & 29.866 & 0.000 \\
\hline $\begin{array}{l}21 \text { Patient developed new pressure } \\
\text { injury }\end{array}$ & $58 / 84$ & $69.05 \%$ & $79 / 87$ & $90.80 \%$ & 12.700 & 0.000 \\
\hline $\begin{array}{l}22 \text { Inform the postanesthesia care } \\
\text { unit (PACU) staff that } \\
\text { patient'svision and peripheral } \\
\text { nerve function must be assessed } \\
\text { after recovery }\end{array}$ & $0 / 84$ & $0.00 \%$ & $84 / 87$ & $96.55 \%$ & 159.410 & 0.000 \\
\hline
\end{tabular}

Table 5 shows the evaluations of the checklist by 72 nurses. $91.7 \%$ nurses thought the checklist was easy to use, while only $8.3 \%$ felt it was difficult to use. A majority thought that the checklist improved general anesthesia and prone position surgery safety and nursing care quality ( $97.2 \%$ and $90.3 \%$ respectively), and $93.1 \%$ agreed that the checklist helped prevent a general anesthesia and prone positional injury. Only $16.7 \%$ of nurses thought that it would take a long time to complete the checklist. A large majority ( $94.4 \%)$ would want the checklist to be used if they were having a general anesthesia and prone position operation, while only four respondents (5.6\%) disagreed with this statement. 
Table 5

Nurse Evaluation of the GAPPNC ( $\mathrm{N}=72)$

\begin{tabular}{|lllll|}
\hline Evaluation & Agree & \multicolumn{2}{c|}{$\begin{array}{l}\text { Disagree, } \\
\text { neutral or no } \\
\text { answer }\end{array}$} \\
\cline { 2 - 5 } & $\mathbf{n}$ & $\%$ & $\mathbf{n}$ & $\%$ \\
\hline The checklist was easy to use & 66 & $91.7 \%$ & 6 & $8.3 \%$ \\
\hline The checklist improved prone position safety & 70 & $97.2 \%$ & 2 & $0.28 \%$ \\
\hline The checklist improved prone position nursing care quality & 65 & $90.3 \%$ & 7 & $9.7 \%$ \\
\hline The checklist took a long time to complete & 12 & $16.7 \%$ & 60 & $83.3 \%$ \\
\hline $\begin{array}{l}\text { If I were having a prone position and general anesthesia operation, I } \\
\text { would want the checklist to be used }\end{array}$ & 68 & $94.4 \%$ & 4 & $5.6 \%$ \\
\hline The checklist helped prevent prone position injury & 67 & $93.1 \%$ & 5 & $6.9 \%$ \\
\hline
\end{tabular}

\section{Discussion}

Our study found that the GAPPNC is an effective tool for translating evidence into practice and standardizing the general anesthesia and prone positioning nursing process and practice. International prone position guidelines were recognized as standard of care for patient positioning care[2], while some recommendations by the CPGs were hard to apply to daily practice due to their complex content or incompatibility with local clinical practice[12]. The WHO therefore recommended that health care providers use a medical checklist for translating evidence into practice[24]. We followed the WHO recommend medical checklist development model to develop a GAPPNC based on high-quality CPGs, multidisciplinary expert opinions, and frontline nurse experience. The checklist established four pause points to check 22 necessary items during the prone position nursing process, which can assist nurse to provide standardized, continuous, and evidence-based prone positioning care in daily practice.

Implementation of the GAPPNC was associated with significant improvement in the delivery of essential prone positional practices and improved nursing quality. The rate of the successful delivery of 22 essential practices significantly improved. The delivery rate of 14 measures achieved a statistically significant improvement. These findings are similar to those of other studies[25]. Previous prone position studies or training usually aim to prevent one particular complication or to introduce the prone positioning method[7, 14, 15], but not analyze the high-risk factors and measures during each stage of prone positioning. As a result, the nurse's prone positioning theoretical and practice level knowledge depends on their own knowledge and experience with this position. We therefore divided the prone positioning nursing process into 4 stages and identified 22 necessary items for patient safety. This tool can help the nurse quickly understand the whole prone positioning care procedure and its essential measures, and then provide comprehensive and safe prone positioning care as part of daily practice[26, 27]. The quality of nursing in this position has consequently greatly improved. 
Nurses who used the checklist had a generally positive view of the tool. Most of them felt that the checklist was easy to use and recognized its value in ensuring patient safety. This may also explain why almost all nurses responded that they wanted the checklist to be used during their own care, including some who against using the checklist. This fundamental perception of the value of a checklist at providing safe patient positioning care suggests that a well-designed checklist and implementation program can be successful at achieving nurse acceptance and use[28]. We believe that our research process can be used as an example for future similar checklist development and implementation studies.

\section{Limitations And Future Research}

This study was performed at only one hospital for half a year. The checklist's effects of increasing the implementation of high importance measures, improving nursing quality, and transforming CPGs have been affirmed to some extent, but its long-term effects, especially at decreasing the incidence of complications, remains to be verified. A variety of similar studies have shown that the long-term use of a medical checklist can effectively improve safety awareness, avoid medical errors, and reduce the incidence of complications and mortality[29]. It is therefore necessary to perform multi-center studies in the future.

\section{Conclusions}

In summary, our study developed a GAPPNC for use by the circulating nurse based on a scientific checklist development model and 6 high-quality CPGs. This checklist can improve the delivery of evidence-based practice, translate such evidence into practice, standardize the nursing process, and be positively perceived by most nurses.

\section{Abbreviations}

PI

Pressure injuries

POVL

Postoperative vision loss

PPNI

Perioperative peripheral nerve injuries

GAPPNC

General anesthesia and prone position nursing checklist

OR

Operating room

PACU

Postanesthesia care unit

\section{Declarations}


Availability of data and materials

The datasets used and/or analyzed during the current study are available from the corresponding author on reasonable request.

\section{Acknowledgements}

The authors would like to appreciate the cooperation of the nurses working at the Sir Run Run Shaw Hospital of Zhejiang University School of Medicine.

\section{Funding}

This study was supported by the Sir Run Run Shaw Hospital Nursing Research Foundation (202130HLGL). The sponsors had no further role in the study design, data analysis and interpretation, the dating of the manuscript or the decision to submit this article for publication.

\section{Author information}

Affiliations

Operating Room Department, Sir Run Run Shaw Hospital, School of Medicine, Zhejiang University, Hangzhou 310016, People's Republic of China

Jianshu Cai, Xiaoling Huang

School of Nursing, Xiang Nan University, 25 Renminxi Road, Beihu District, Chenzhou, 423000, People's Republic of China

Lifang $\mathrm{He}$

Contributions

Study concept and design Jianshu Cai. Analysis and interpretation of data: Jianshu Cai and Xiaoling Huang. Drafting the manuscript: Jianshu Cai. Critical revision of the manuscript Jianshu Cai and Lifang He. The authors declare that this manuscript has not been presented to any other journal for publication. All authors read and approved the final manuscript.

Corresponding author

Correspondence to Lifang He3316113@zju.edu.cn.

\section{Ethics declarations}

Ethics approval and consent to participate 
The study was conducted according to the guidelines of the Declaration of Helsinki and approved by the Ethics Committee of Sir Run Run Shaw Hospital of Zhejiang University School of Medicine『201907250970. All nurses were informed that their participation was voluntary. Informed written consent forms were taken from all participants before participation.

Consent for publication

Not applicable.

Competing interests

The authors declare that there are no conflicts of interest.

\section{References}

1. Simpson Al, Vaghela KR, Brown $\mathrm{H}$, et al. Reducing the Risk and Impact of Brachial Plexus Injury Sustained From Prone Positioning-A Clinical Commentary. J Intensive Care Med 2020;35:1576-82.

2. Spruce, L. (2021). Positioning the Patient. AORN journal, 114(1), 75-84. https://doi.org/10.1002/aorn.13442

3. VAN Wicklin SA. Systematic Review and Meta-Analysis of Prone Position on Intraocular Pressure in Adults Undergoing Surgery. Int J Spine Surg 2020;14:195-208.

4. Amorim Correa, J.L., Acioly, M.A. (2018). The Enigma of Orbital Compartment Syndrome After Lumbar Spine Surgery in the Prone Position: Case Report and Literature Review. World Neurosurg, $110,309$.

5. Luo M, Long XH, Wu JL, et al. Incidence and Risk Factors of Pressure Injuries in Surgical Spinal Patients: A Retrospective Study[J]. J Wound Ostomy Continence Nurs, 2019,46(5):397-400. DOI: 10.1097/WON.0000000000000570.

6. Khong B, Goh BC, Phang LY, et al. Operating room nurses' self-reported knowledge and attitude on perioperative pressure injury[J]. Int Wound J, 2020,17(2):455-465. DOI: 10.1111/iwj.13295.

7. Woodfin KO, Johnson C, Parker R, et al. Use of a Novel Memory Aid to Educate Perioperative Team Members on Proper Patient Positioning Technique[J]. AORN J, 2018,107(3):325-332. DOI: 10.1002/aorn.12075.

8. Oliveira VM, Piekala DM, Deponti GN, et al. Safe prone checklist: construction and implementation of a tool for performing the prone maneuver[J]. Rev Bras Ter Intensiva, 2017,29(2):131-141.

9. WHO Guidelines for Safe Surgery 2009: Safe Surgery Saves Lives[M]. Geneva:World Health Organization,2009.

10. Hou Y, Di X, Concepcion C, et al. Establishment and implementation of safety check project for invasive procedures outside the operating room[J]. Int J Nurs Sci, 2021,8(2):199-203. DOI: 10.1016/j.jijns.2021.02.002. 
11. Gama CS, Backman C, de Oliveira AC. Impact of Surgical Checklist on Mortality, Reoperation, and Readmission Rates in Brazil, a Developing Country, and Canada, a Developed Country[J]. J Perianesth Nurs, 2020,35(5):508-513.e2. DOI: 10.1016/j.jopan.2020.01.015.

12. McArthur C, Bai Y, Hewston P, Giangregorio L, Straus S, Papaioannou A. Barriers and facilitators to implementing evidence-based guidelines in long-term care: a qualitative evidence synthesis. Implement Sci. 2021;16(1):70.

13. Salkind $E M$, . A novel approach to improving the safety of patients undergoing lumbar laminectomy. AANA J. 2013;81(5):389-93.

14. Chui J, Murkin JM, Posner KL, et al. Perioperative Peripheral Nerve Injury After General Anesthesia: A Qualitative Systematic Review[J]. Anesth Analg, 2018,127(1):134-143. DOI:

10.1213/ANE.0000000000003420.

15. Haleem S, Mihai R, Rothenfluh DA, et al. Preventing iatrogenic facial pressure ulcers during spinal surgery: Prospective trial using a novel method and review of literature[J]. Int Wound J, 2020,17(5):1391-1395. DOI: 10.1111/iwj.13402.

16. Kwee MM, Ho Y, Rozen WM. The prone position during surgery and its complications: a systematic review and evidence-based guidelines. Int Surg. 2015;100(2):292.

17. Weiser TG, Haynes AB, Lashoher A, et al. Perspectives in quality: designing the WHO Surgical Safety Checklist. Int J Qual Health Care. 2010;22(5):365-370.

18. Spector JM, Lashoher A, Agrawal P, et al. Designing the WHO Safe Childbirth Checklist program to improve quality of care at childbirth. Int J Gynaecol Obstet. 2013;122(2):164-168.

19. WHO Guidelines for Safe Surgery 2009: Safe Surgery Saves Lives. 2009. Geneva. World Health Organization.

20. Haynes AB, Weiser TG, Berry WR, et al. A surgical safety checklist to reduce morbidity and mortality in a global population. N Engl J Med. 2009;360(5):491.

21. Spector, J.M., Lashoher, A., Agrawal, P., et al. (2013). Designing the WHO Safe Childbirth Checklist program to improve quality of care at childbirth. Int J Gynaecol Obstet, 122,164-168.

22. Brouwers, M.C., Kho, M.E., Browman, G.P., et al. (2010). Development of the AGREE II, part 1: performance, usefulness and areas for improvement. Cmaj Canadian Medical Association Journal, 182,1045-1052.

23. Van Wicklin, S.A. (2019). Guideline for positioning the patient. Guidelines for Perioperative Practice(pp.1-72). Denver (CO): AORN, Inc.

24. Röhsig V, Maestri RN, Parrini Mutlaq MF, et al. Quality improvement strategy to enhance compliance with the World Health Organization Surgical Safety Checklist in a large hospital: Quality improvement study. Ann Med Surg (Lond). 2020;55:19.

25. Tsai H, Tsai Y. Development, validation and testing of a nursing home to emergency room transfer (NHERT) checklist. J Clin Nurs. 2017;27(3). 
26. Lane H, Campbell K, Zhang A, et al. Development and Interrater Reliability of an Observational School Environment Checklist: A Practical, Comprehensive Tool to Assess Healthy Eating and Physical Activity Opportunities in Schools. Health Promot Pract. 2021:15248399211014501.

27. Vena A, Bouza E, Corisco R, et al. Efficacy of a "checklist" intervention bundle on the clinical outcome of patients with candida bloodstream infections: a quasi-experimental pre-post study. Infect Dis Ther. 2020;9(1):119-135.

28. BMJ quality \& safety, 20(1), 102-107. https://doi.org/10.1136/bmjqs.2009.040022

29. Storesund A, Haugen AS, Flaatten H, Nortvedt MW, Sfteland E. Clinical Efficacy of Combined Surgical Patient Safety System and the World Health Organization's Checklists in Surgery: A Nonrandomized Clinical Trial. JAMA Surg. 2020.

\section{Figures}

\section{Assemble evidence on possible areas of improvement \& critical omissions}

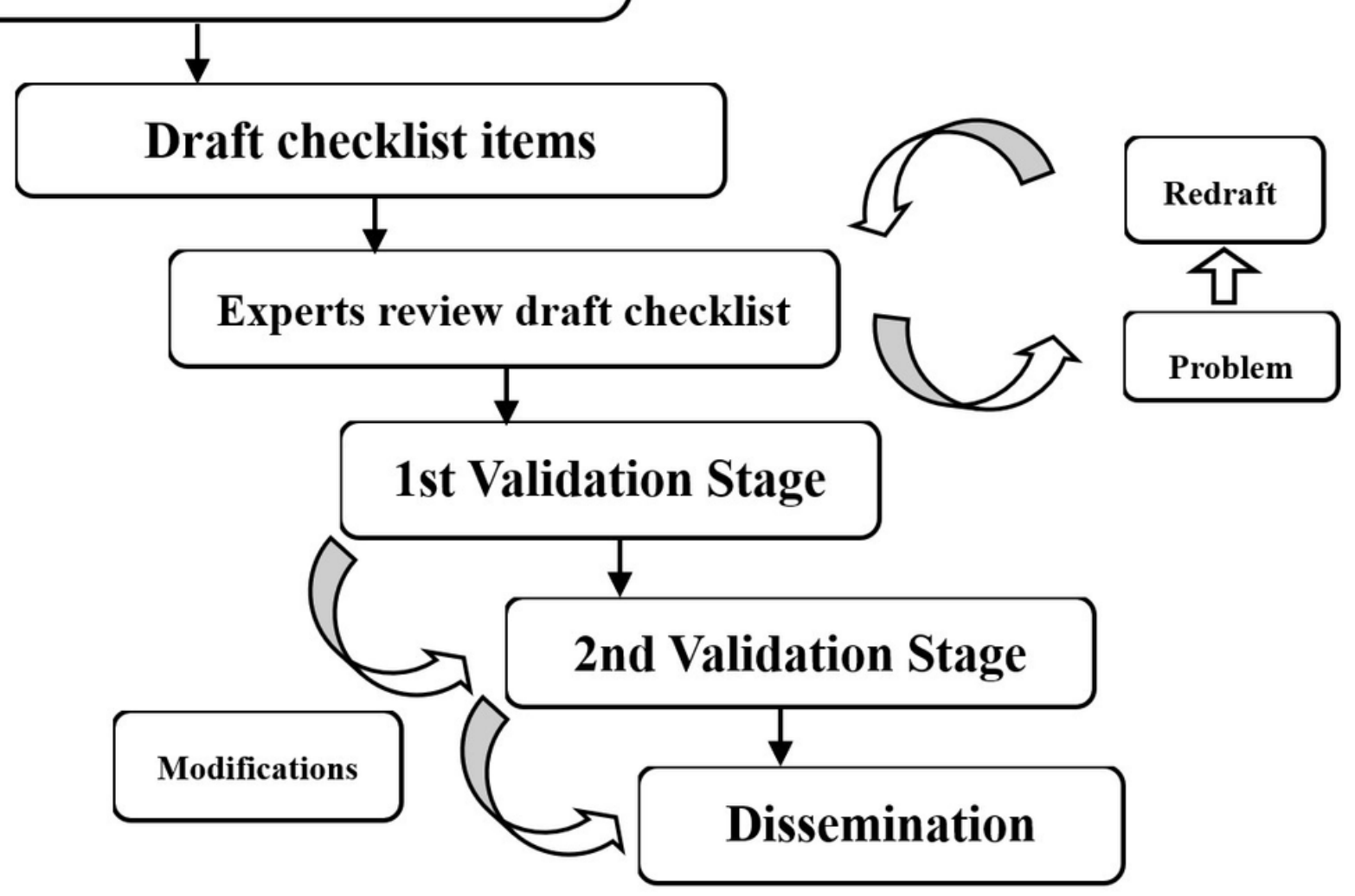

Figure 1

The WHO Checklist Development Model 


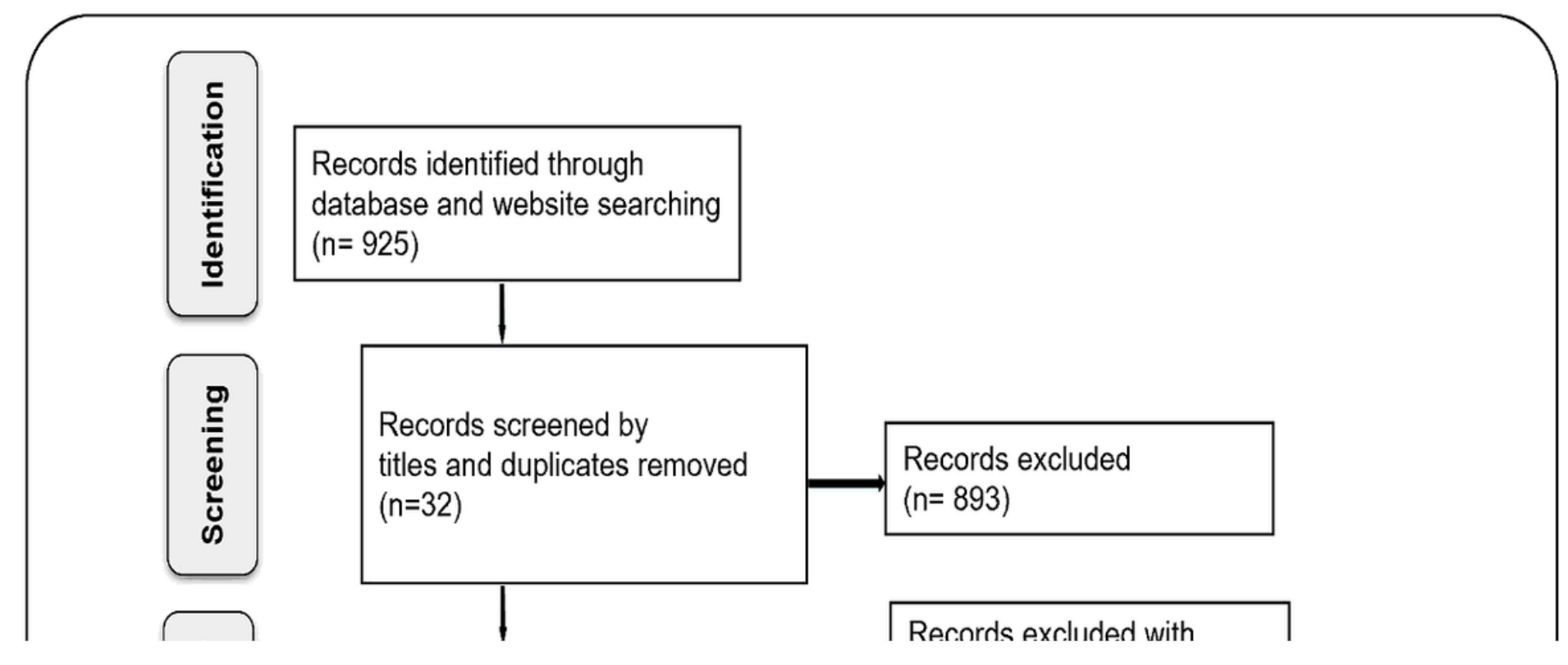

Figure 2

The Search Process 


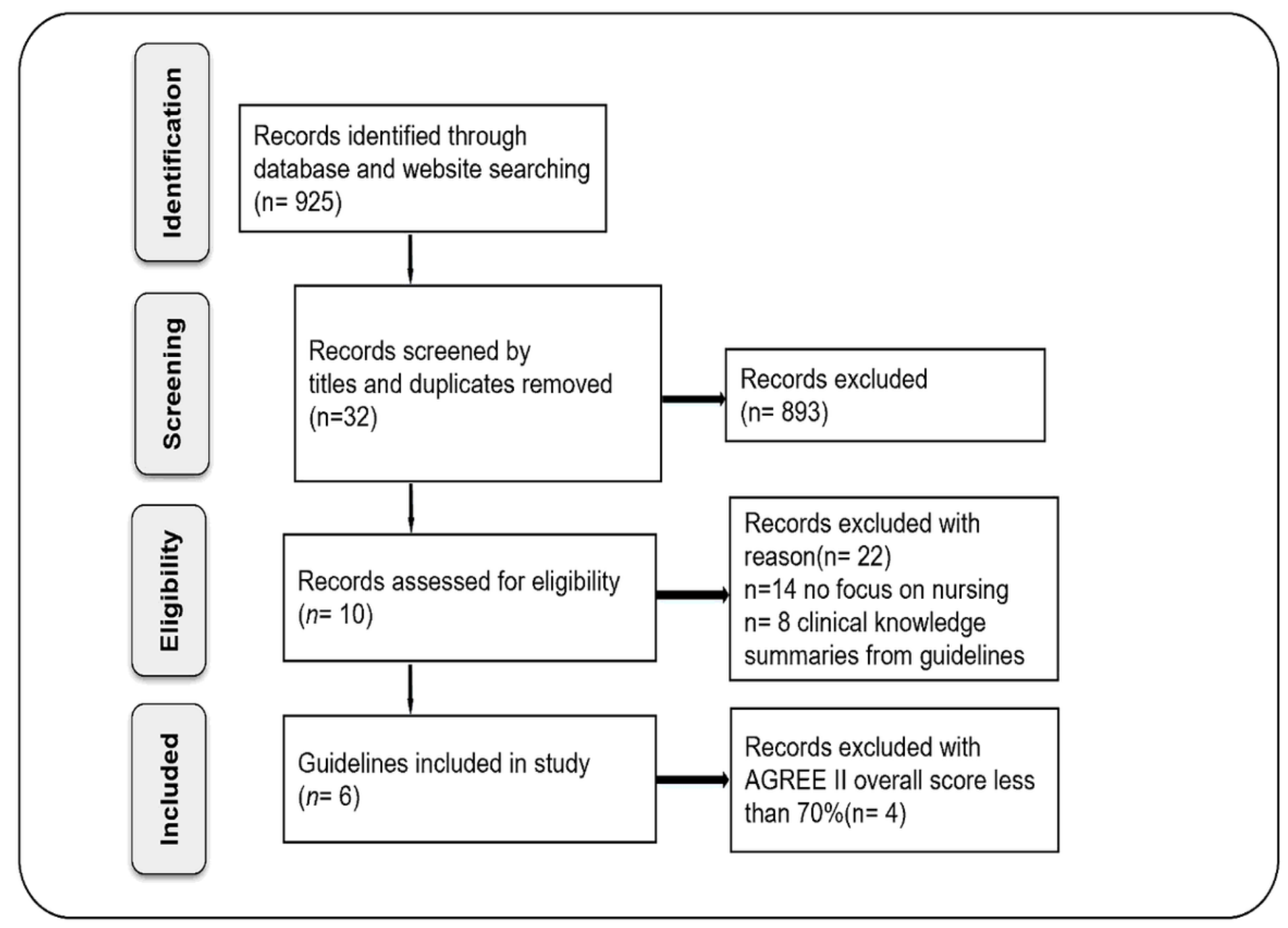

Figure 2

The Search Process

\section{Supplementary Files}

This is a list of supplementary files associated with this preprint. Click to download.

- supplementary.docx 